\title{
Accuracy of Timed Up and Go Test for screening risk of falls among community-dwelling elderly
}

\author{
Acurácia do Timed Up and Go Test para rastrear risco de \\ quedas em idosos da comunidade
}

Tiago S. Alexandre', Débora M. Meira², Natália C. Rico³, Simone K. Mizuta ${ }^{3}$

\begin{abstract}
Objective: To determine the accuracy of the Timed Up and Go Test (TUGT) for screening the risk of falls among community-dwelling elderly individuals. Method: This is a prospective cohort study with a randomly by lots without reposition sample stratified by proportional partition in relation to gender involving 63 community-dwelling elderly individuals. Elderly individuals who reported having Parkinson's disease, a history of transitory ischemic attack, stroke and with a Mini Mental State Exam lower than the expected for the education level, were on a wheelchair and that reported a single fall in the previous six months were excluded. The TUGT, a mobility test, was the measure of interested and the occurrence of falls was the outcome. The performance of basic activities of daily living (ADL) and instrumental activities of daily living (IADL) was determined through the Older American Resources and Services, and the sociodemographic and clinical data were determined through the use of additional questionnaires. Receiver Operating Characteristic Curves were used to analyze the sensitivity and specificity of the TUGT. Results: Elderly individuals who fell had greater difficulties in ADL and IADL $(p<0.01)$ and a slower performance on the TUGT $(p=0.02)$. No differences were found in socio-demographic and clinical characteristics between fallers and non-fallers. Considering the different sensitivity and specificity, the best predictive value for discriminating elderly individuals who fell was 12.47 seconds [( $R R=3.2) 95 \% \mathrm{Cl}$ : 1.3-7.7]. Conclusions: The TUGT proved to be an accurate measure for screening the risk of falls among elderly individuals. Although different from that reported in the international literature, the 12.47 second cutoff point seems to be a better predictive value for Brazilian elderly individuals.
\end{abstract}

Keywords: elderly; falls; TUGT; sensitivity; specificity; physical therapy.

\section{Resumo}

Objetivo: Determinar a acurácia do Timed Up and Go Test (TUGT) para rastrear risco de quedas em idosos da comunidade. Método: Tratase de um estudo de coorte prospectivo com amostra sorteada aleatoriamente, sem reposição e estratificada por partilha proporcional em relação ao sexo de 63 idosos da comunidade. Excluíram-se idosos com doença de Parkinson, ataque isquêmico transitório, acidente vascular encefálico, Miniexame do Estado Mental inferior ao considerado normal de acordo com a escolaridade, movimentação exclusiva por cadeira de rodas e relato de uma queda nos seis meses anteriores à primeira entrevista. O TUGT, um teste de mobilidade, foi a medida testada, e o desfecho, a ocorrência de queda. Mensuraram-se atividades básicas (ABVD) e instrumentais de vida diária (AIVD) pela Older American Resources and Services e dados sociodemográficos e clínicos por questionário complementar. Para analisar a sensibilidade e a especificidade do TUGT, utilizou-se a Receiver Operating Characteristic Curves (ROC). Resultados: Os idosos que caíram tinham maior dificuldade na execução de ABVD e AIVD $(p<0,01)$ e desempenho mais lento no TUGT ( $p=0,02)$. Quanto às características sociodemográficas e clínicas, não houve diferença entre idosos que caíram e os que não caíram. Considerando as diferentes sensibilidades, especificidades e razões de verossimilhança, o melhor valor preditivo para discriminar idosos que caíram foi 12,47 segundos [(RR=3,2) IC95\%: 1,3-7,7]. Conclusão: O TUGT é acurado para rastrear risco de quedas em idosos. O cut-off de 12,47 segundos, embora diferente da literatura internacional, parece ser um melhor valor preditivo para idosos brasileiros.

Palavras-chave: idosos; quedas; TUGT; sensibilidade; especificidade; fisioterapia

Received: 11/21/2011 - Revised: 03/14/2012 - Accepted: 04/13/2012

Department of Epidemiology, Universidade de São Paulo (USP), São Paulo, SP, Brazi

2 Physical Therapy, Speech Pathology and Occupational Therapy Department, USP, São Paulo, SP, Brazi

${ }^{3}$ Physical Therapist, São Paulo, SP, Brazil

Correspondence to: Tiago da Silva Alexandre, Rua José Gonçalves, 73, Parque Industrial, CEP 12237-710, São José dos Campos, SP, Brasil, e-mail: tsfisioalex@gmail.com 


\section{Introduction $: \because$.}

The accelerated ageing of the population worldwide has led to serious public health problem such as falls among elderly individuals ${ }^{1}$. In Brazil, the prevalence of falls among the elderly in 2006 was $36.4 \%$ among women and $22.6 \%$ among men, whereas the incidence in the period between 2000 and 2006 was $22.7 \%$ among women and $14.9 \%$ among men².

There are numerous risk factors for falling in this population, such as muscle weakness, past history of falls, gait, balance, visual and cognitive impairment, osteoarthritis, depression and age greater than 80 years $^{3}$. Moreover, the risk of serious adverse outcomes stemming from a fall, such as a fear of falling, fractures, reduced functionality, frailty, admission to nursing homes and death, is greater among elderly individuals ${ }^{1}$.

The updated guidelines of the American and British Geriatric Society for the Prevention of Falls recommend the use of a clinical algorithm that establishes a systematic decision-making process in the assessment of the risk of falls and the selection of interventions for elderly individuals who seek healthcare services. One of the recommendations is the use of the Timed Up and Go Test (TUGT) for the assessment of gait and balance ${ }^{4}$. The TUGT is fast, easy-to-apply and has been validated for screening the risk of falls among elderly individuals $\mathrm{s}^{5,6}$. However, the validation of the TUGT has not yet been performed for the Brazilian population. While encouraging, the evidence of the TUGT accuracy in the identification of risk of falls among communitydwelling elderly individuals is based on retrospective studies and should therefore be taken with caution.

Thus, the aim of the present study was to conduct a prospective investigation to determine the accuracy of the TUGT for screening the risk of falls among community-dwelling elderly individuals.

\section{Method $: \because$.}

The sample size calculation was based on a $5 \% \alpha$ error, $95 \%$ confidence interval (CI) and the prevalence of falls in the elderly described on a previous study $(28.6 \%)^{7}$. The number of elderly individuals registered with the Family Health Program (FHP) in the city of Taubaté (Sao Paulo, Brazil) was obtained from the Basic Care Information System, which indicated 2149 individuals on November 29, 2007. The sample was stratified by gender to ensure the representativeness of both genders in accordance with the council's population.

The final sample was determined randomly by lots without reposition and consisted of 63 individuals (30 men and 33 women aged 60 years or older) registered with the FHP in the city of Taubaté. The final sample had a sampling fraction of 0.045 and a maximal error of $10.33 \%$.

Six physical therapists were trained to administer the measures under the supervision of a more experienced phusical therapist. Visits to homes were scheduled with the assistance of community health agents from the elderlies' respective Family Health Units. When an individual was not found at home on the first visit, a second visit was scheduled. The home visit involved the reading and signing of the statement of informed consent. Upon agreement to participate, a screening questionnaire with the exclusion criteria was administered.

The definition of falls in the present study was that adopted by the World Health Organization and a report of the Kellogg International Work Group on the Prevention of Elderly Falls. A fall was defined as any event that results in a bodily change that forces an individual to inadvertently land on the ground or a lower level, other than as a consequence of a violent strike, loss of consciousness, sudden onset paralysis or epileptic seizure ${ }^{8}$.

Elderly individuals who reported having Parkinson's disease, with a history of transitory ischemic attack, stroke, and with a Mini Mental State Exam (MMSE) lower than the recommended by Bertolucci et al. ${ }^{9}$ ( $<13$ for illiterate individuals, $<18$ for those with up to 8 years of schooling and $<26$ for those with more than 8 years of schooling), that were on a wheelchair and reported a single fall in the previous six months were excluded from the study.

Among the 63 individuals selected for the sample, 54 reported no falls in the previous six months $(85.7 \%)$ and nine reported more than one fall (14.3\%).

A structured questionnaire was administered to register the following socio-demographic and clinical data: age; gender; marital status; schooling/education; self-reported conditions (systemic arterial hypertension, osteoarthritis, osteoporosis and diabetes) and medications. Although the MMSE was an exclusion criterion, the scores of the included elderly were also recorded.

The Portuguese version of the Older Americans Resources and Services (OARS), the Multidimensional Functional Assessment Questionnaire (BOMFAQ) $)^{10}$, was employed for the assessment of functional state. In the validation study, internal consistency of the subscale evaluating basic activities of daily living (ADL) and instrumental activities of daily living (IADL) was 0.91 , criterion validity ranged from 0.051 to 0.6 and reproducibility was $1.00^{11}$. The BOMFAQ assesses reported difficulties in the performance of 15 activities - eight ADL (getting into and out of bed, eating, combing hair, walking on a flat surface, bathing, dressing, going to the bathroom on time and cutting toenails) and seven IADL (climbing a flight of stairs; taking medications on time, walking close to home, shopping, making 
meals, driving and housecleaning). This instrument has three response options: "I have no difficulty", "I have some difficulty" or "I have a lot of difficulty" in performing the task in question. For analysis purposes, the responses were dichotomized as "no difficulty" and "difficulty" (uniting both latter options). A greater number of compromised activities denoted worse functional capacity.

Mobility was determined by the performance of the TUGT administered by the researchers in the participant's home, who wore his/her usual footwear and used gait-assistance device (GAD) if needed. No physical assistance was given throughout the test. After receiving instructions to walk at his/her habitual gait speed, the participant had to seat on a standardized chair (seat 42 centimeters from ground, back 79 centimeters from ground and arm 60 centimeters from ground), with arms and trunk supported. After the verbal command to begin, the evaluator initiated the chronometer as the participant stood up, walked three meters in a straight line, turned 180 degrees, walked back to the chair and sat down again. The clock was stopped only when the participant was seated in the chair with his/her arms and back supported. The time needed to perform the task was recorded in seconds.

Participants were followed for a one-year period, receiving three additional visits from blinded evaluators who asked about the occurrence of falls in the preceding period. The second, third and fourth visits occurred three, six and 12 months following the administration of the TUGT, respectively, with a leeway of three days after the scheduled date. In order to reduce memory bias, the participants received a log at the end of each contact in which they were to record the date, site and circumstances of any falls. The evaluator collected the log at the end of each visit.

Three losses to follow-up occurred throughout the study (one change of address, one abandonment and one death). Thus, the final sample consisted of 60 elderly individuals (29 males and 31 females).

For the statistical analysis, the Shapiro-Wilk test was used to demonstrate that the TUGT and other quantitative variables did not exhibit normal distribution ( $\mathrm{p} \leq 0.001$ ). Thus, the MannWhitney test was used for the comparison of mean values between the groups of fallers and non-fallers and the chi-square test was used for the analysis of differences in proportion. The level of significance was set at 0.05 . Receiver operating characteristic (ROC) curves were constructed for the analysis of sensitivity and specificity. The sensitivity of a test describes how well it correctly identifies subjects with a condition of interest, whereas specificity indicates the frequency that the test is negative in the absence of a condition of interest ${ }^{12}$. The relative risk of falls and respective CI were calculated based on the cutoff point identified. The Stata $9^{\circledR}$ statistical package was used for the statistical analysis.
This study received approval from the ethics committee of Universidade de Taubaté, Taubaté, SP, Brazil, under process number 105/09.

\section{Results $\because:$}

Throughout the follow-up period, 21 participants (11 women and 10 men) suffered at least one fall. No differences were found in socio-demographic and clinical characteristics between fallers and non-fallers. The participants who fell had a slower performance on the TUGT ( $\mathrm{p}=0.02)$ and greater difficulties in the performance of ADL and IADL ( $p<0.01)$ (Table 1$)$.

The best cutoff points for both sensitivity and specificity were around 0.70 (Figure 1). Analyzing the different sensitivity, specificity and likelihood ratio values (Table 2), the best predictive value for discriminating elderly individuals who fell was 12.47 seconds, with $73.7 \%$ sensitivity, $65.8 \%$ specificity and area under the ROC curve of 0.68 (95\%CI:0.54-0.83) (Figure 2). Considering 12.47 seconds as the best predictive value of the TUGT, the positive predictive value (50\%) and negative predictive value (84.4\%) were calculated based on Table 3. The positive predictive value designates the proportion of individuals with 12.47 or more seconds on the TUGT who actually fell during the follow-up period, whereas the negative predictive

Table 1. Association between sample characteristics and occurrence of falls.

\begin{tabular}{lcc}
\hline Characteristics of Sample & $\begin{array}{c}\text { Fallers } \\
(\mathrm{n}=19)\end{array}$ & $\begin{array}{c}\text { Non-Fallers } \\
(\mathrm{n}=41)\end{array}$ \\
\hline Socio-demographic & & \\
\hline Age & $\begin{array}{c}66.68 \pm 5.57 \\
(60-82)\end{array}$ & $\begin{array}{c}66.36 \pm 4.60 \\
(60-75)\end{array}$ \\
\hline Gender (female) & $52.63 \%$ & $51.22 \%$ \\
\hline Marital status (with conjugal life) & $47.37 \%$ & $51.22 \%$ \\
\hline Schooling & $1.78 \pm 2.37$ & $2.90 \pm 3.38$ \\
& $(0-8)$ & $(0-14)$ \\
\hline Clinical & & \\
\hline Systemic arterial hypertension & $36.84 \%$ & $60.98 \%$ \\
(yes) & $31.58 \%$ & $24.39 \%$ \\
\hline Osteoarthritis (yes) & $31.58 \%$ & $12.20 \%$ \\
\hline Osteoporosis (yes) & $15.79 \%$ & $7.32 \%$ \\
\hline Diabetes (yes) & $23.73 \pm 3.70$ & $23.75 \pm 4.27$ \\
\hline Mini Mental State Examination & $(15-29)$ & $(14-29)$ \\
\hline Medications in use & $1.73 \pm 2.35$ & $1.80 \pm 1.47$ \\
& $(0-10)$ & $(0-5)$ \\
\hline Functional & & \\
\hline Older Americans Resources and & $4.15 \pm 3.38$ & $1.19 \pm 1.63^{*}$ \\
Services & $(0-12)$ & $(0-6)$ \\
\hline Timed Up and Go Test & $13.18 \pm 2.51$ & $11.95 \pm 2.86^{*}$ \\
$(8-23.02)$
\end{tabular}

Mean \pm standard deviation; minimum and maximum values between parentheses; $n=$ number of elderly individuals surveyed; * ${ }^{2}$ ignificant difference between fallers and non-fallers (Mann-Whitney; $p \leq 0.05$ ). 


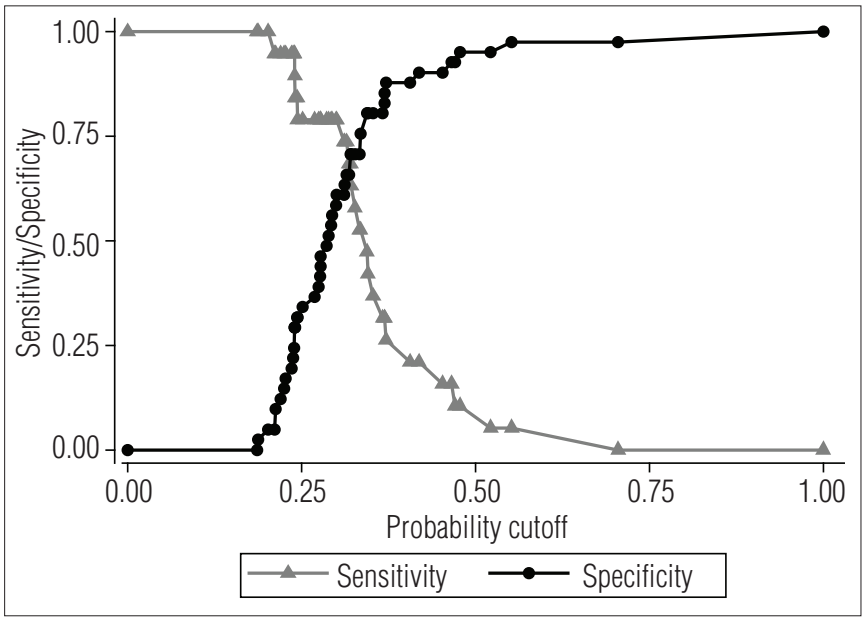

Figure 1. Relationship between the sensitivity and specificity and the probability cutoff of the TUGT as a predictor of falls among elderly individuals in the population.

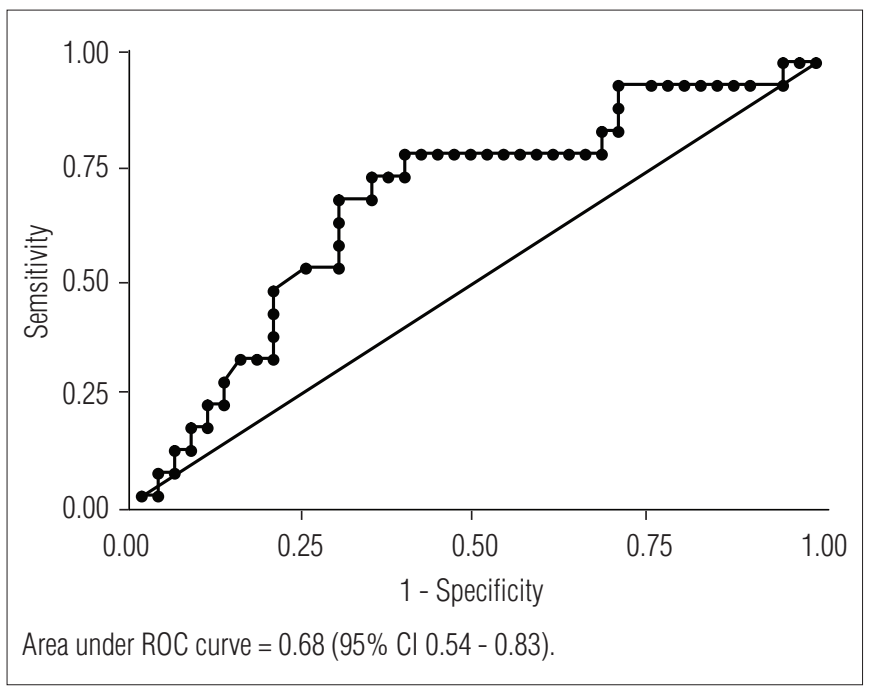

Figure 2. ROC curve of TUGT as predictor of falls among elderly individuals.

value designates the proportion of individuals with less than 12.47 seconds on the TUGT who did not fall during the followup period. The risk of falls was 3.2-fold ( $\mathrm{RR}=3.2$; $95 \% \mathrm{CI}$ : 1.3-7.7) greater among those with a performance on the TUGT equal to or greater than 12.47 seconds.

Comparisons of mean age and performance on the TUGT in the groups of fallers and non-fallers were made between the present investigation and studies that determined predictive value for the occurrence of the outcome. For such, the comparison of means test was employed, using the number of fallers and non-fallers in each study and respective mean and standard deviation values through the ttesti command of the Stata $9^{\circledR}$ statistical program.

The mean ages in the present study for fallers and nonfallers [66.68 ( $\mathrm{SD}=5.57)$ and $66.36(\mathrm{SD}=4.60)$, respectively] were lower than those in the study by Shumway-Cook, Brauer and
Woollacott ${ }^{6}$ [86.2 $(\mathrm{SD}=6.40)$ and $\left.78.4(\mathrm{SD}=5.8)\right]$, Rose, Jones and Lucchese ${ }^{13}$ [78.4 (SD=6.5) and $\left.76.7(\mathrm{SD}=6.2)\right]$ and Gunter et al. ${ }^{14}$ [one-time fallers 78.27 (SD=5.03), frequent fallers 77.74 $(\mathrm{SD}=5.28)$ and non-fallers $75.93(\mathrm{SD}=5.94)$ ]. The differences in age between the present investigation and other studies were statistically significant for both groups $(\mathrm{p}<0.001)$.

Regarding the TUGT, elderly fallers performed the test in 22.2 ( $\mathrm{SD}=9.3$ ) seconds in the study by Shumway-Cook, Brauer and Woollacott ${ }^{6}$ and 12.3 (SD=3.9) seconds in the study by Rose, Jones and Lucchese ${ }^{13}$. One-time fallers performed the test in $8.91(\mathrm{SD}=1.34)$ seconds and frequent fallers performed the test in $9.21(\mathrm{SD}=1.31)$ seconds in the study by Gunter et al. ${ }^{14}$ Fallers in the present study performed the test in $13.18(\mathrm{SD}=2.51)$ seconds. Non-fallers performed the test in $8.4(\mathrm{SD}=1.7)$ seconds in the study by Shumway-Cook, Brauer and Woollacott ${ }^{6}, 8.2$ $(\mathrm{SD}=1.8)$ seconds in the study by Rose, Jones and Lucchese ${ }^{13}$ 7.54 ( $\mathrm{SD}=1.21$ ) seconds in the study by Gunter et al. ${ }^{14}$ and 11.95 $(\mathrm{SD}=2.86)$ seconds in the present study. The differences in the performance on the TUGT between studies were statistically significant in both groups $(\mathrm{p}<0.001)$, except between the fallers in the present study and those in the study by Rose, Jones and Lucchese $^{13}(\mathrm{p}=0.18)$.

\section{Discussion $\because \because$.}

The results presented in this study validate a predictive value of 12.47 seconds on the TUGT as an indicator of the risk of falls among elderly individuals. This cutoff point is different from values found in the literature.

The knowledge on the prevalence of falls and the proportion of men and women in the population of interested allowed the recruitment of a representative sample. This careful planning ensured greater reliability in relation to the sample investigated. The exclusion of individuals that had fallen a single time in the preceding six months maximized the selection of non-fallers and recurrent fallers, thereby eliminating those who may have fallen due to extrinsic factors. This decision was based on arguments in the literature that recurring falls are more predictive and may have more serious consequences than a single fall ${ }^{15,16}$. The same method has been employed in previous studies analyzing the accuracy of the TUGT for screening the risk of falls ${ }^{6,13}$.

The exclusion of individuals with positive screening for cognitive impairment and neurological conditions ensured the inclusion of a less frail sample with no evident postural balance disorders. This exclusion criteria has also been employed in previous studies ${ }^{6,13}$ as it allows the identification of the predictive value on the TUGT for screening community-dwelling 
Table 2. Coordinates of ROC curve for determination of predictive cutoff point of falls among 60 elderly individuals treated in basic health care in the city of Taubaté (SP, Brazil).

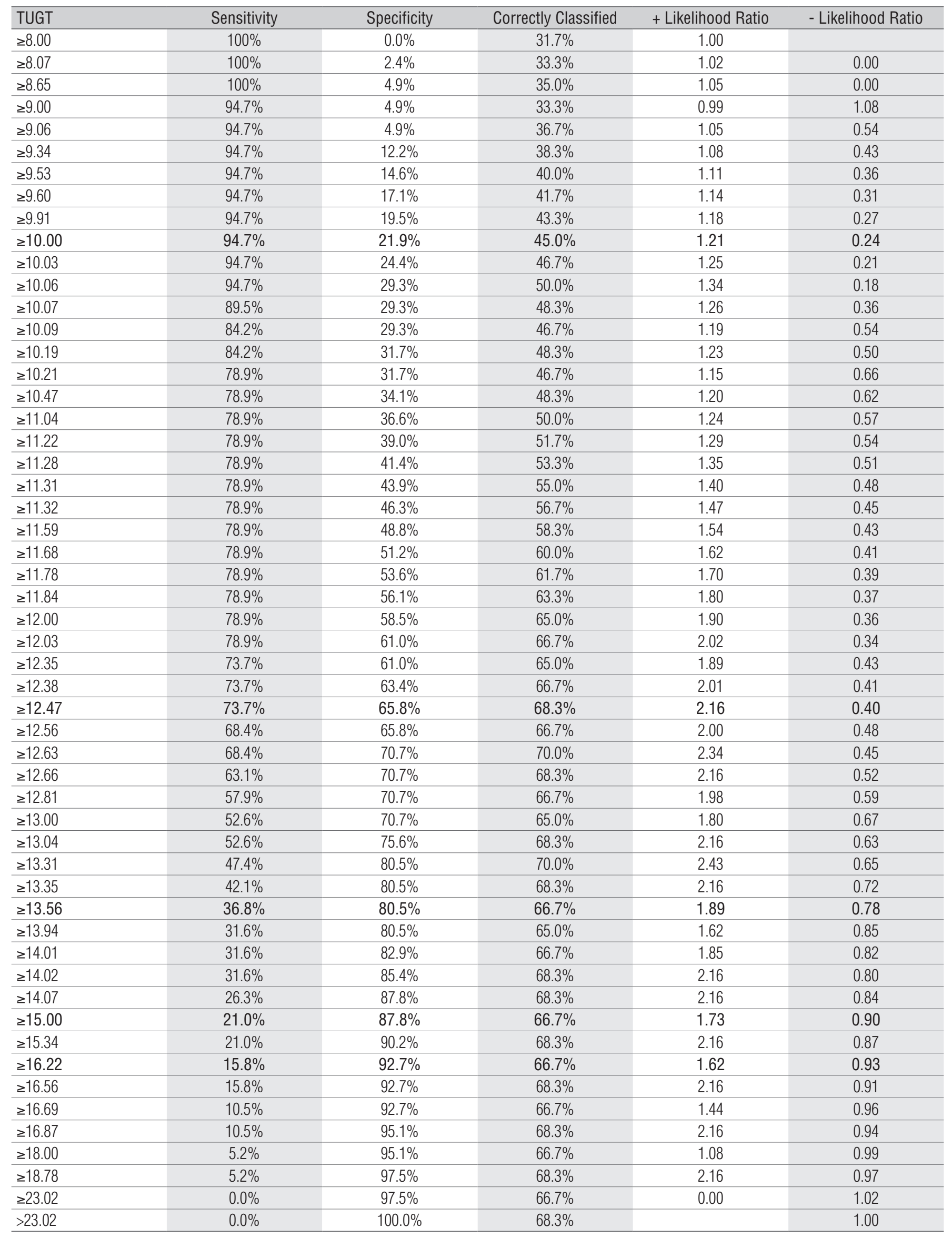


Table 3. Two by two table of all elderly individuals who fell and who did not fall during an one year follow up classified based on the TUGT cut off point.

\begin{tabular}{lccc}
\multicolumn{3}{c}{ Falls } & \\
\hline TUGT & Yes & No & Total \\
\hline$\geq 12.47$ seconds & 14 & 14 & 28 \\
\hline$<12.47$ seconds & 5 & 27 & 32 \\
\hline Total & 19 & 41 & 60 \\
\hline
\end{tabular}

individuals with no clear postural balance compromise and frailty, but that are known to be under imminent risk of falling. This patient group needs to be identified in order to offer timely orientation and preventive strategies.

In the present study, the predictive value of $12.47 \mathrm{sec}-$ onds detected 14 (73.7\%) of the 19 individuals who fell in the year following the TUGT. This predictive value is lower than the 13.5 seconds described by Shumway-Cook, Brauer and Woollacott ${ }^{6}$ Using the cut off described by Shumway-Cook, Brauer and Woollacott ${ }^{6}$, only seven of the 19 individuals who fell would have been detected (Table 2). This is a $50 \%$ lower percentage than that achieved with the predictive value of 12.47 seconds.

If the cutoff point of 10 seconds proposed by Rose, Jones and Lucchese ${ }^{13}$ had been used, 18 of the 19 individuals having suffered falls would have been identified. However, 32 of the 41 individuals who had not fallen would have been mistakenly identified. Thus, the sensitivity of the test would have been increased in detriment to its specificity.

Divergences among cutoff points for the risk of falls may be attributed to the different study designs employed and the period in which falls were investigated. While the present investigation was a prospective study with a one-year follow-up period, the studies by Shumway-Cook, Brauer and Woollacott ${ }^{6}$, Rose, Jones and Lucchese ${ }^{13}$ and Gunter et al. ${ }^{14}$ were retrospective investigations, the first of which inquired regarding the occurrence of falls in the six months prior to the administration of the TUGT and the latter two inquired regarding the occurrence of falls in the 12 months prior to the administration of the TUGT.

Another explanation for this divergence appears to be related to the profile of the samples included in each study. There were no differences in the ages of the groups of fallers and nonfallers in the present investigation or the studies by Rose, Jones and Lucchese ${ }^{13}$ and Gunter et al. ${ }^{14}$. However, in the study by Shumway-Cook, Brauer and Woollacott ${ }^{6}$, the mean age of the group who reported falls in the six months prior to the administration of the TUGT was higher than that of the group of nonfallers. Moreover, it was the highest age range of both fallers and non-fallers among all the studies analyzed.

There were also differences among the studies in the proportion of individuals who used a GAD, indicating distinctions in the prior risk of falls. According to guidelines ${ }^{1}$, the risk of falls is 2.6-fold greater among individuals who use such device.
Among the 15 elderly individuals who reported falls in the study by Shumway-Cook, Brauer and Woollacott ${ }^{6}, 12$ used a GAD. In the study by Rose, Jones and Lucchese ${ }^{13}, 32$ of the 63 elderly individuals who reported falls used a GAD. In the present study, only one participant used a GAD.

Thus, the more advanced age and the vulnerability to falls in the sample of the study by Shumway-Cook, Brauer and Woollacott ${ }^{6}$ could have led to a slower performance on the TUGT in the group of fallers and, consequently, the higher cutoff point reported by the authors. However, despite being older, the elderly individuals in the group of non-fallers in the study by Rose, Jones and Lucchese ${ }^{13}$ performed the TUGT faster than the non-fallers in the present study, while no difference in performance was found among the fallers in the two studies. This may be explained by the instructions given to the participants regarding the test. The present study followed the recommendation by Podsiadlo and Richardson ${ }^{5}$ and participants were instructed to perform the test at their habitual gait speed, whereas the participants in the study by Rose, Jones and Lucchese ${ }^{13}$ were instructed to perform the test as quickly as safely possible. This difference in instruction would explain the faster performance and lower cutoff point reported by Rose, Jones and Lucchese ${ }^{13}$.

Shimada et al. ${ }^{17}$ analyzed the capacity of the TUGT to screen the risk of falls in a one-year retrospective study involving Japanese elderly individuals at adult daycare centers, in which the majority of participants exhibited disability and frailty. The higher cutoff point of 16 seconds identified the risk of falls with $53 \%$ sensitivity and $63 \%$ specificity. Moreover, those with a performance greater than 16 seconds had a $50 \%$ greater chance of suffering falls. In a six-month prospective cohort study involving frail elderly individuals living in long-stay institutions in Sweden, Nordin et al..$^{18}$ found that a performance on the TUGT greater than 15 seconds identified the risk of falls with $96 \%$ sensitivity and $32 \%$ specificity.

Therefore, the predictive value of 13.5 seconds may be more indicated for older elderly individuals, whereas 12.47 seconds may be more indicated for younger elderly individuals. Likewise, a performance greater than 10 seconds may be more recommended when the elderly participant is instructed to walk as fast as safely possible, whereas the 12.47 second cutoff point may be more indicated when the test is performed at the individual's habitual gait speed. However, a performance of greater than 15 seconds may be recommended to screen the risk of falls among frail elderly individuals.

The results of a meta-analysis conducted by Bohannon ${ }^{19}$ support the hypothesis that age affects the performance of the test. The authors analyzed 21 studies and identified reference values for the TUGT with regard to the capacity of this test for measuring mobility among elderly individuals and 
concluded that there are differences in performance between different age groups. Elderly individuals between 60 and 69 years of age performed the test in 8.1 seconds (7.1-9.0), those between 70 and 79 years of age performed the test in 9.2 seconds (8.2-10.2) and those between 80 and 99 years of age performed the test in 11.3 seconds (10.0-12.7). Since advance in age reduces gait speed, consequently increasing the time needed to perform the test, it is likely that age also affects the predictive value regarding the risk of falling.

Chiu, Au-Yeung and $\mathrm{Lo}^{20}$ conducted a paired case-control study to compare four important mobility and balance assessment tools: Berg Balance Scale, Tinetti Mobility Score, Elderly Mobility Scale and TUGT. The authors concluded that the TUGT should not be recommended for discriminating between individuals who suffered a single fall and those who suffered no falls, due to its low sensitivity (59\% for the 20.1 second cutoff point). In the present study, individuals who fell a single time were excluded from the analysis, which impedes the comparison of results between the two studies. Nevertheless, on the above mentioned study, the mean age of the individuals who reported a single fall ( 82.12 years; $\mathrm{SD}=8.19$ years) and those who reported multiple falls ( 82.86 years; $\mathrm{SD}=6.63$ years) was much higher than the age of the participants in the present study.

Haines et al. ${ }^{21}$ conducted a prospective multi-center study involving hospitalized patients in Australia at geriatric and rehabilitation hospitals in which the outcome was falls after hospitalization. With a 30 second cutoff point, sensitivity was $80 \%$ and specificity was $22 \%$, which led the authors to conclude that the TUGT may not be capable of screening the risk of falls among hospitalized elderly individuals with acute clinical conditions, as falls could be caused by other factors beyond mobility and balance deficits. Thus, the TUGT is more efficacious in screening the risk of falls in community-dwelling elderly individuals.

Methodological issues may be involved in the differences found in cutoff points between the present investigation and previous studies. While Shumway-Cook, Brauer and Woollacott ${ }^{6}$ and Rose, Jones and Lucchese ${ }^{13}$ used logistic regression analysis, Gunter et al. ${ }^{14}$ used Wilk's Lambda analysis and the present investigation and the studies by Chiu, Au-Yeung and $\mathrm{Lo}^{20}$, Haines et al. ${ }^{21}$, Shimada et al. ${ }^{17}$ and Nordin et al..$^{18}$ determined the validity of the predictive value using ROC curves.

An important limitation of the present study was that the sample was not stratified by age and frailty status. Moreover, the reports of falls are dependent on memory. However, the use of a $\log$ to record of falls was designed to minimize memory bias. The exclusion of elderly individuals with neurologic disease and those with a single fall in the previous six months limits the generalization of the results to these patient groups.

The variability in the measure merits particular attention. The cutoff point recommended in this study was 12.47 seconds. In clinical practice, the use of a cutoff point with two decimal points is unviable and healthcare professionals who administer this test and examine different TUGT sensitivity and specificity values will naturally opt for values rounded to the nearest whole second.

In conclusion, the TUGT proved to be an accurate measure for screening the risk of falls among elderly individuals. Although different from values reported in the international literature, the 12.47 second cut-off seems to be a better predictive value for Brazilian elderly individuals. The TUGT can be used in basic healthcare and in the outpatient network as a screening test for the risk of falls among community-dwelling elderly individuals.

\section{References $: \because$.}

1. Guideline for the prevention of falls in older persons. American Geriatrics Society, British Geriatrics Society, and American Academy of Orthopaedic Surgeons Panel on Falls Prevention. J Am Geriatr Soc. 2001;49(5):664-72

2. Telles ACM. Prevalência, incidência, fatores preditivos e impacto das quedas entre as pessoas idosas no município de São Paulo: uma análise longitudinal. [dissertação]. São Paulo: Escola de Enfermagem, Universidade de São Paulo; 2008.

3. Muir SW, Berg K, Chesworth B, Klar N, Speechley M. Balance impairment as a risk factor for falls in community-dwelling older adults who are high functioning: a prospective study. Phys Ther. 2010;90(3):338-47

4. Panel on Prevention of Falls in Older Persons, American Geriatrics Society and British Geriatrics Society. Summary of the updated American Geriatrics Society/British Geriatrics Society clinical practice guideline for prevention of falls in older persons. J Am Geriatr Soc. 2011;59(1): $148-57$

5. Podsiadlo D, Richardson S. The timed "Up \& Go": a test of basic functional mobility for frail elderly persons. J Am Geriatr Soc. 1991;39(2):142-8.
6. Shumway-Cook A, Brauer S, Woollacott M. Predicting the probability for falls in communitydwelling older adults using the timed up \& go test. Phys Ther. 2000;80(9):896-903.

7. Lebrão ML, Laurenti R. Saúde, bem-estar e envelhecimento: 0 estudo SABE no Município de São Paulo. Rev Bras Epidemiol. 2005;8(2):127-41.

8. The prevention of falls in later life. A report of the Kellogg International Work Group on the prevention of falls by the elderly. Dan Med Bull.1987;34 Suppl 4:1-24.

9. Bertolucci PHF, Brucki SMD, Campacci SR, Juliano Y. 0 mini-exame do estado mental em uma população geral- impacto da escolaridade. Arq Neuropsiquiatr. 1999;52(1):1-7.

10. Blay SL, Ramos LR, Mari JJ. Validity of a Brazilian version of the Older Americans Resources and Services (OARS) mental health screening questionnaire. J Am Geriatr Soc. 1988;36(8):687-92.

11. Rodrigues RMC. Validação da versão em português europeu de questionário de avaliação funcional multidimensional de idosos. Rev Panam Salud Pública. 2008;23(2):109-15.

12. Sackett DL. The rational clinical examination. A primer on the precision and accuracy of the clinical examination. JAMA. 1992;267(19):2638-44. 
13. Rose DJ, Jones CJ, Lucchese N. Predicting the probability of falls in community-residing older adults using the 8-Foot Up and Go: a new measure of functional mobility. J Aging Phys Act. 2002;10(4):466-75

14. Gunter KB, White KN, Hayes WC, Snow CM. Functional mobility discriminates nonfallers from one-time and frequent fallers. J Gerontol A Biol Sci Med Sci. 2000;55(11):M672-6.

15. Chandler JM. Invited commentary. Phys Ther. 2000;76(6):584-5.

16. Nevitt MC, Cummings SR, Kidd S, Black D. Risk factors for recurrent nonsyncopal falls: A prospective study. JAMA. 1989;261(18):2663-8.

17. Shimada H, Suzukawa M, Tiedemann A, Kobayashi K, Yoshida H, Suzuki T. Which neuromuscular or cognitive test is the optimal screening tool to predict falls in frail community-dwelling older people? Gerontology. 2009;55(5):532-8
18. Nordin E, Lindelöf N, Rosendahl E, Jensen J, Lundin-Olsson L. Prognostic validity of the Timed Up-and-Go Test, a modified Get Up-and-Go Test, staff's global judgement and fall history in evaluating fall risk in residential care facilities. Age Ageing. 2008;37(4):442-8.

19. Bohannon RW. Reference values for the Timed Up and Go Test: a descriptive meta-analysis J Geriatr Phys Ther. 2006;29(2):64-8

20. Chiu AY, Au-Yeung SS, Lo SK. A comparison of four functional tests in discriminating fallers from non-fallers in older people. Disabil Rehabil. 2003;25(1):45-50

21. Haines T, Kuys SS, Morrison G, Clarke J, Bew P. Balance impairment not predictive of falls in geriatric rehabilitation wards. J Gerontol A Biol Sci Med Sci. 2008;63(5):523-8. 